\title{
The Role of digital subtraction angiography in the ventricular spot sign on the computed tomography angiography
}

\author{
Jun-Soo Cho', Sang-Uk Kim'1, Hyung-Jin Lee', Ji-Ho Yang' ', II-Woo Lee', Jae-Hoon Sung ${ }^{2}$ \\ 'Department of Neurosurgery, Deajeon St. Mary's Hospital, College of Medicine, The Catholic University of Korea, \\ Daejeon, Republic of Korea, '2Department of Neurosurgery, St. Vincent's Hospital, College of Medicine, The Catholic \\ University of Korea, Suwon, Republic of Korea
}

Objective : The spot sign on computed tomography angiography is little known about the relationship between the spot sign and the results of cerebral angiography We retrospectively analyzed the spot sign, digital subtraction angiography results, and other factors.

Material and Methods : From December 2009 to May 2014, DSA was performed in $52 \mathrm{ICH}$ patients with non-specific location or abnormalities on CTA findings. 26 of those patients, whose initial CTA showed the spot sign, were analyzed. Two groups, one with the spot sign in the ventricle (Group A) and others with the spot sign in another location (Group B) were statistically compared.

Results : The mean age of the study subjects was 46.9 years (range, 15 to 80 years) and the percentage of males was 53.8\%. Thirteen of 26 patients had $\mathrm{ICH}$ without intraventricular hemorrhage, and 6 patients had co-existing IVH. In 17 cases, the DSA results were negative. Seven patients were diagnosed with pseudoaneurysms, and two cases showed developmental venous anomalies. Group A consisted of the 8 patients $(30.8 \%)$ who showed the spot sign in a ventricle. The number of pseudoaneurysms was statistically significantly higher in Group A than in Group B (71.4\% versus 28.6\%; OR, 13.3; 95\% Cl, 1.7-103.8 P $=0.014$ ). All three patients who underwent endovascular treatment were members of Group A (P = 0.022), whereas most (92.3\%) of those in Group B underwent surgical evacuation. $(P=0.030)$.

Conclusion : When CTA shows the spot sign in a ventricle, it is a clue that an existing underlying vascular lesion requires endovascular treatment.

Keywords Cerebral hemorrhage, Cerebral angiography, computed tomography angiography, spot sign
J Cerebrovasc Endovasc Neurosurg. 2019 March;21(1):24-32

Received : 12 July 2018

Revised : 16 September 2018

Accepted : 16 March 2019

\section{Correspondence to Sang Uk Kim}

Department of Neurosurgery, Deajeon St. Mary's Hospital, College of Medicine, The

Catholic University of Korea

Tel : $+82-42-220-9525$

Fax : +82-31-245-5208

E-mail : tkddnr79@hanmail.net

ORCID : http://orcid.org/0000-0002-5195-1215
This is an Open Access article distributed under the terms of the Creative Commons Attribution NonCommercial License (http://creativecommons.org/licenses/by-nc/3.0) which permits unrestricted noncommercial use, distribution, and reproduction in any medium, provided the original work is properly cited.

\section{INTRODUCTION}

Spontaneous Intracerebral hemorrhage (ICH) accounts for about $15 \%$ of all strokes and has a 30 -day mortality rate of up to $50 \%{ }^{16) 18)}$. Several reports have proposed the computed tomography angiography (CTA) 'spot sign' as a predictive radiological marker of hematoma expansion ${ }^{3) 56)}$. 
The 'spot sign' on CTA was first described in 2007 by Wada et al., and is defined as "tiny, enhancing foci within hematomas, with or without contrast extravasation $^{\prime 18)}$. This is generally interpreted as focal sites of extravasation, a focus of arrested bleeding, or a microvascular abnormality ${ }^{6}$; however, the exact pathophysiology of the spot sign unknown.

In this study, we assessed digital subtraction angiography (DSA) when a patient's CTA showed the spot sign and analyzed the correlation between the spot sign and the existence of a possible vascular lesion that would lead to hematoma expansion and other factors.

\section{MATERIALS AND METHODS}

This study was approved by the Institutional Review Board of our institution (VC16RISI0019). Between December 2009 and May 2014, DSA was performed in $52 \mathrm{ICH}$ patients with atypical lobar ICH or abnormalities on CTA findings. Twenty-six of these patients, whose initial CTA showed the spot sign, were analyzed. The spot sign was defined as a 1- to-2 $\mathrm{mm}$ high-density lesion within the hematoma on maximum intensity projection (MIP) CTA images. All studies were evaluated by 2 more neuroradiologists and/or neurosurgeons to assess the presence or absence of the CTA spot sign. Cerebral DSA was performed on a SIEMENS biplane neuroangiographic unit (Artis Zee SIEMENS, Germany) by one or two neurointerventionists.

Cases with a hematoma greater than $60 \mathrm{ml}$, midline shifting of over $10 \mathrm{~mm}$, unstable vital signs, or poor mental status (Glasgow coma scale $(\mathrm{GCS})<6$ ) that needed emergency operations were excluded from the analysis. We also excluded that tumor bleeding, subarachnoid hemorrhage (SAH) due to ruptured aneurysm, and hemorrhage from previously known vascular abnormalies such as arteriovenous malformation (AVM), dural arteriovenous fistula (AVF), and Moyamoya disease.
Data on each patient were collected retrospectively, including: sex, age at presentation, type of hemorrhage, location of the spot sign, antiplatelet use, history of hypertension, diabetes mellitus (DM) and dyslipidemia, GCS score, blood pressure, clotting profile, platelet count at presentation, result of DSA, and type of treatment.

We performed statistical analyses using SPSS version 18.0 (IBM Corporation, Armonk, NY, USA). Continuous variables are presented as means and standard deviations, and variables were compared between the two subgroups with the Chi-squared test and Mann-Whitney $\mathrm{U}$ test, as appropriate. A $\mathrm{p}$ value of $<0.05$ was considered statistically significant.

\section{RESULTS}

\section{Patients characteristics and ICH location}

We collected data on these 26 patients over the course of 54 months (Table 1). As shown in Tables 2 and 3, the mean age of the study subjects was 46.9 years (range, 15 to 80 years) and the percentage of males was $53.8 \%$. Thirteen of $26(50 \%)$ patients had ICH without any kind of hemorrhage and 6 patients (23.1\%) had coexisting intraventricular hemorrhage (IVH). Pure IVH was detected in 7 patients $(26.9 \%)$.

The ICH locations of total 19 patients were distributed as shown in Table 2. ; 8 cases $(42.1 \%)$ in supratentorial lesion, 3 cases $(15.8 \%)$ in infratentorial lesion, 5 cases $(26.3 \%)$ in the deep seated portions (basal ganglia and thalamus) and 3 case (15.8\%) in atypical location.

\section{Spot sign and DSA finding}

In each 8 patients $(30.7 \%)$, the location of the spot sign was the ventricle and the frontal area, and in 5 patients $(19.2 \%)$, the location of the spot sign was the deep location (basal ganglia and thalamus). In two patients each had the spot sign in the cerebellum and the temporal area. In one patient, the location of the spot sign was the parietal area. In 17 of 26 cases (65.4\%), the DSA results were negative. Seven patients 
Table 1. Characteristics of patients: type of hemorrhage, location, result of Digital subtraction angiography (DSA)

\begin{tabular}{|c|c|c|c|c|c|c|}
\hline Patient & Sex & Age & Type of hemorrhage & Spot sign location & Result of DSA & Treatment \\
\hline 1 & $M$ & 70 & $\mathrm{ICH}$ & Frontal lobe & Negative & Surgical Tx. \\
\hline 2 & $\mathrm{~F}$ & 65 & $\mathrm{ICH}$ & Frontal lobe & Negative & Surgical Tx. \\
\hline 3 & $M$ & 35 & $\mathrm{ICH}$ & Frontal lobe & Negative & Surgical Tx. \\
\hline 4 & $\mathrm{~F}$ & 66 & $\mathrm{ICH}$ & Basal ganglia & Negative & Surgical Tx. \\
\hline 5 & $M^{f}$ & 54 & $\mathrm{ICH}$ & Basal ganglia & Negative & Surgical Tx. \\
\hline 6 & $M$ & 43 & $\mathrm{ICH}$ & Basal ganglia & Negative & Surgical Tx. \\
\hline 7 & $\mathrm{~F}$ & 24 & $\mathrm{ICH}$ & Basal ganglia & Negative & Surgical Tx. \\
\hline 8 & M & 27 & $\mathrm{ICH}$ & Temporal lobe & Negative & Surgical Tx. \\
\hline 9 & M & 63 & $\mathrm{ICH}$ & Temporal lobe & Negative & Conservative Tx. \\
\hline 10 & $\mathrm{~F}$ & 49 & $\mathrm{ICH}$ & Cerebellar lobe & Negative & Conservative Tx. \\
\hline 11 & $\mathrm{~F}$ & 41 & IVH & Ventricle & Negative & Conservative Tx. \\
\hline 12 & $\mathrm{~F}$ & 37 & IVH & Ventricle & Negative & Conservative Tx. \\
\hline 13 & $\mathrm{~F}$ & 62 & IVH & Ventricle & Negative & Conservative Tx. \\
\hline 14 & $M$ & 67 & IVH & Ventricle & Negative & Conservative Tx. \\
\hline 15 & $M$ & 49 & $\mathrm{ICH}$ with $\mathrm{IVH}$ & Frontal lobe & Negative & Conservative Tx. \\
\hline 16 & $M$ & 63 & $\mathrm{ICH}$ with IVH & Ventricle & Negative & Conservative Tx. \\
\hline 17 & $M$ & 37 & $\mathrm{ICH}$ with $\mathrm{IVH}$ & Thalamus & Negative & Conservative Tx. \\
\hline 18 & $M$ & 23 & $\mathrm{ICH}$ & Frontal lobe & DVA & Surgical Tx. \\
\hline 19 & $\mathrm{~F}$ & 46 & $\mathrm{ICH}$ & Cerebellar lobe & DVA & Surgical Tx. \\
\hline 20 & $\mathrm{~F}$ & 25 & $\mathrm{ICH}$ & Frontal lobe & Pseudoaneurysm & Surgical Tx. \\
\hline 21 & $\mathrm{~F}$ & 30 & $\mathrm{ICH}$ with IVH & Frontal lobe & Pseudoaneurysm & Surgical Tx. \\
\hline 22 & $\mathrm{~F}$ & 15 & $\mathrm{ICH}$ with $\mathrm{IVH}$ & Frontal lobe & Pseudoaneurysm & Surgical Tx. \\
\hline 23 & $M$ & 18 & $\mathrm{ICH}$ with $\mathrm{IVH}$ & Parietal lobe & Pseudoaneurysm & Endovascular Tx. \\
\hline 24 & $\mathrm{~F}$ & 80 & IVH & Ventricle & Pseudoaneurysm & Conservative Tx. \\
\hline 25 & M & 72 & $\mathrm{IVH}$ & Ventricle & Pseudoaneurysm & Endovascular Tx. \\
\hline 26 & $M$ & 58 & $\mathrm{IVH}$ & Ventricle & Pseudoaneurysm & Endovascular Tx. \\
\hline
\end{tabular}

$M$ Male, F Female, $I C H$ Intracranial hemorrhage, $I V H$ Intraventricular hemorrhage, DVA Developmental venous anomaly

Table 2. Hemorrhage type, location of the spot sign, and pseudoaneurysm

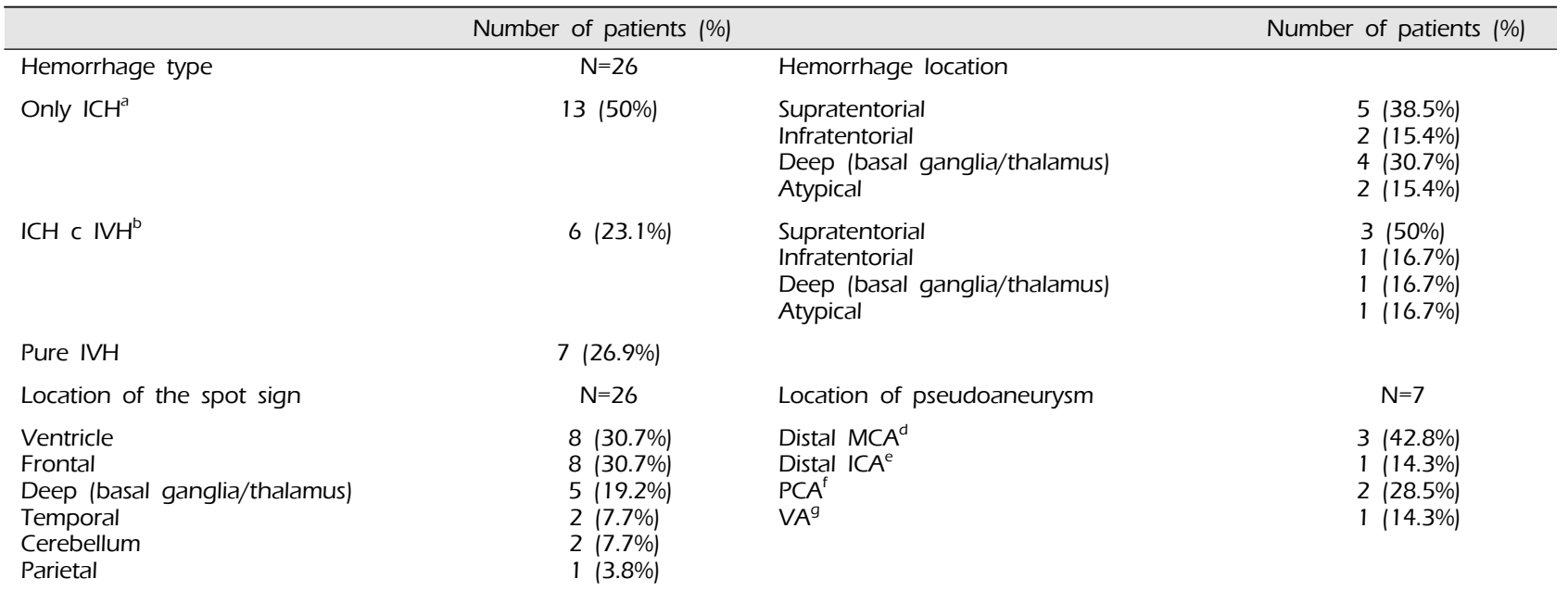

Abbreviations: ICH, Intracerebral hemorrhage; IVH, Intravetricular hemorrhage; SAH, Subarachnoid hemorrhage; MCA, Middle cerebral artery; ICH, Internal cerebral artery; PCA, Posterior cerebral artery; VA, Vertebral artery

(26.9\%) were diagnosed with pseudoaneurysms, defined as a saccular dilation in the distal portion of the vessels, and two cases showed developmental venous anomalies (DVA). Of the 7 patients with pseudoaneurysm, Each 3 patients (42.8\%) presented with pure IVH and ICH with IVH, and one was seen in only ICH. but most (10/17 58.8\%) of the patients with neg- ative findings on angiography were in the only $\mathrm{ICH}$ group, pure IVH was 4 patients and the remaining 3 patients were in the ICH with IVH.

Half $(13 / 26)$ of the patients were treated surgically. Three patients underwent endovascular treatment and the other patients (10 of 26) received conservative care, such as medical therapy and extraventricular 
Table 3. Characteristics of the two groups that have the spot sign in the ventricle and the others

\begin{tabular}{|c|c|c|c|c|}
\hline & Total $(n=26)$ & $\begin{array}{l}\text { Spot sign in a ventricle }(\mathrm{N}=8) \\
\text { Group } A\end{array}$ & $\begin{array}{l}\text { Spot sign in the others }(\mathrm{N}=18) \\
\text { Group B }\end{array}$ & $\mathrm{p}$-value \\
\hline $\begin{array}{l}\text { Demographic } \\
\text { Age (range) }\end{array}$ & $46.9(15-80)$ years & $50.4(18-80)$ years & $45.3(15-70)$ years & 0.487 \\
\hline Male sex & $14(53.8 \%)$ & $4(28.6 \%)$ & $10(71.4 \%)$ & 1.000 \\
\hline 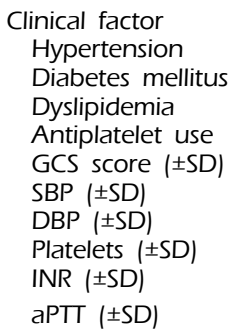 & $\begin{array}{c}12(46 \%) \\
7(26.9 \%) \\
5(19.2 \%) \\
7(26.9 \%) \\
11( \pm 0.7) \\
149.8( \pm 7.7) \mathrm{mmHg} \\
84( \pm 4.0) \mathrm{mmHg} \\
245.7( \pm 13.3) \times 10^{9} \mathrm{cells} / \mathrm{L} \\
1.03( \pm 0.09) \\
23.9( \pm 0.94) \mathrm{sec}\end{array}$ & $\begin{array}{c}4(33.3 \%) \\
3(42.9 \%) \\
0(0 \%) \\
3(42.9 \%) \\
10.6( \pm 1.3) \\
128( \pm 9.7) \mathrm{mmHg} \\
75.4( \pm 8.7) \mathrm{mmHg} \\
231.4( \pm 26.9) \times 10^{9} \mathrm{cells} / \mathrm{L} \\
1.04( \pm 0.03) \\
22.5( \pm 1.21) \mathrm{sec}\end{array}$ & $\begin{array}{cc}8 & (66.7 \%) \\
4 & (57.1 \%) \\
5 & (100 \%) \\
4 & (57.1 \%) \\
11.2( \pm 0.8) \\
156.4( \pm 9.6) \mathrm{mmHg} \\
87.9( \pm 4.1) \mathrm{mmHg} \\
252.1( \pm 15.4) \times 10^{9} \mathrm{cells} / \mathrm{L} \\
1.02( \pm 0.02) \\
24.5( \pm 1.24) \mathrm{sec}\end{array}$ & $\begin{array}{l}1.000 \\
0.635 \\
0.281 \\
0.635 \\
0.732 \\
0.079 \\
0.325 \\
0.304 \\
0.289 \\
0.359\end{array}$ \\
\hline $\begin{array}{l}\text { DSA result } \\
\text { Negative } \\
\text { pseudoaneurysm } \\
\text { DVA }\end{array}$ & $\begin{aligned} 17 & (65.4 \%) \\
7 & (26.9 \%) \\
2 & (7.7 \%)\end{aligned}$ & $\begin{array}{l}3(17.6 \%) \\
5 \text { (71.4\%) } \\
0 \text { (0\%) }\end{array}$ & $\begin{aligned} 14 & (82.4 \%) \\
2 & (28.6 \%) \\
2 & (100 \%)\end{aligned}$ & $\begin{array}{l}0.078 \\
0.014 \\
1.000\end{array}$ \\
\hline $\begin{array}{l}\text { Treatment } \\
\text { Surgical } \\
\text { endovascular } \\
\text { Conservative care }\end{array}$ & $\begin{aligned} 13 & (50.0 \%) \\
3 & (11.1 \%) \\
10 & (37 \%)\end{aligned}$ & $\begin{array}{ll}1 & (7.7 \%) \\
3 & (100 \%) \\
4 & (40.0 \%)\end{array}$ & $\begin{aligned} 12 & (92.3 \%) \\
0 & (0 \%) \\
6 & (60.0 \%)\end{aligned}$ & $\begin{array}{l}0.030 \\
0.022 \\
0.664\end{array}$ \\
\hline
\end{tabular}

Abbreviations: SD, Standard deviation; GCS, Glasgow coma scale; SBP, Systolic blood pressure; DBP, Diastolic blood pressure; DVA,

Developmental venous anomaly.

drainage.

\section{Subgroup analysis}

The patients were divided into 2 groups based on initial radiographic features: Group A (8 patients) had a spot sign in the ventricle, and Group B (18 patients) had a spot sign in another site. The characteristics of the patients in Groups A and B are presented in Table 2.

Mean age and the percentage of males were 50.4 years (range, 18 to 70 years) and $28.6 \%$ in Group A, respectively, versus 45.3 years (range, 15 to 70 years) and $71.4 \%$ in Group B. There were no statistically significant differences between the two groups in terms of past history, initial status, and laboratory findings.

The majority (5/8) of the patients in Group A had significant pseudoaneurysms on DSA $(P=0.014)$, and three of those five patients required endovascular treatment $(\mathrm{P}=0.022)$. however, only two of 18 patient showed pseudoaneurysms and none underwent the endovscualr treatment in Group B. Most of surgical treatment was performed significantly in Group B (P $=0.030)$. In the present of spot sign in the ventricle, there were often vascular lesions that could be treated with endovascular procedure and the surgical approach was not easy anatomically from brain cortex to deep in the ventricle.

\section{ILLUSTRATIVE CASES}

\section{Case 1.}

A 54-year-old man presented with $\mathrm{ICH}$ in the left basal ganglia with the spot sign on CTA (Fig. 1). The DSA findings were negative, but a follow-up brain CT scan showed expansion of hematoma. The patient's neurological deterioration aggravated; hence, he underwent surgical treatment.

\section{Case 2.}

A 46-year-old woman presented with $\mathrm{ICH}$ in the left cerebellum with no intraventricular expansion (Fig. 2). The diagnostic angiogram showed DVA. After conservative care for a few days, the hematoma enlarged and her symptoms worsened; she underwent a surgical procedure. 

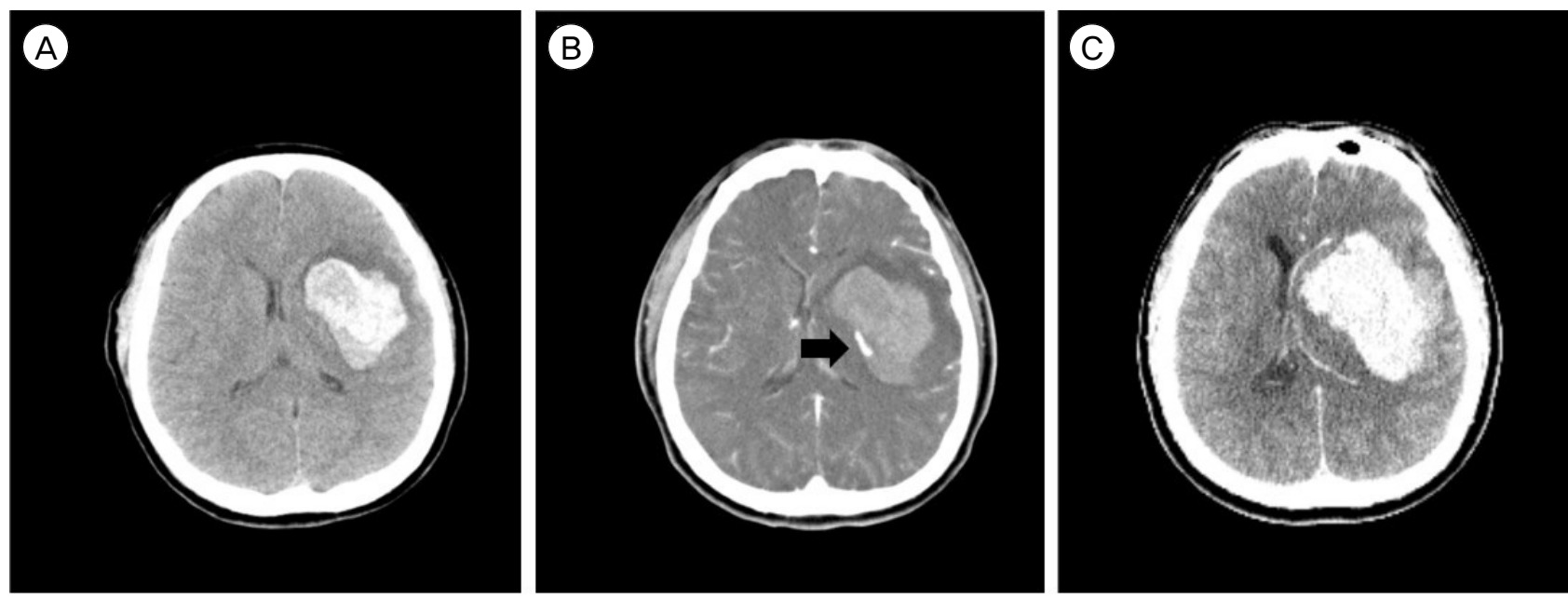

Fig. 1. A 54-year-old male (A) Non-enhanced computed tomography (NECT) shows a left frontal ICH. (B) Hyperdensity apparent on a post contrast CT image (black arrow), called the 'spot sign,' is detected. There is no definite vascular abnormality on DSA. (C) A follow-up brain CT shows expansion of the hematoma
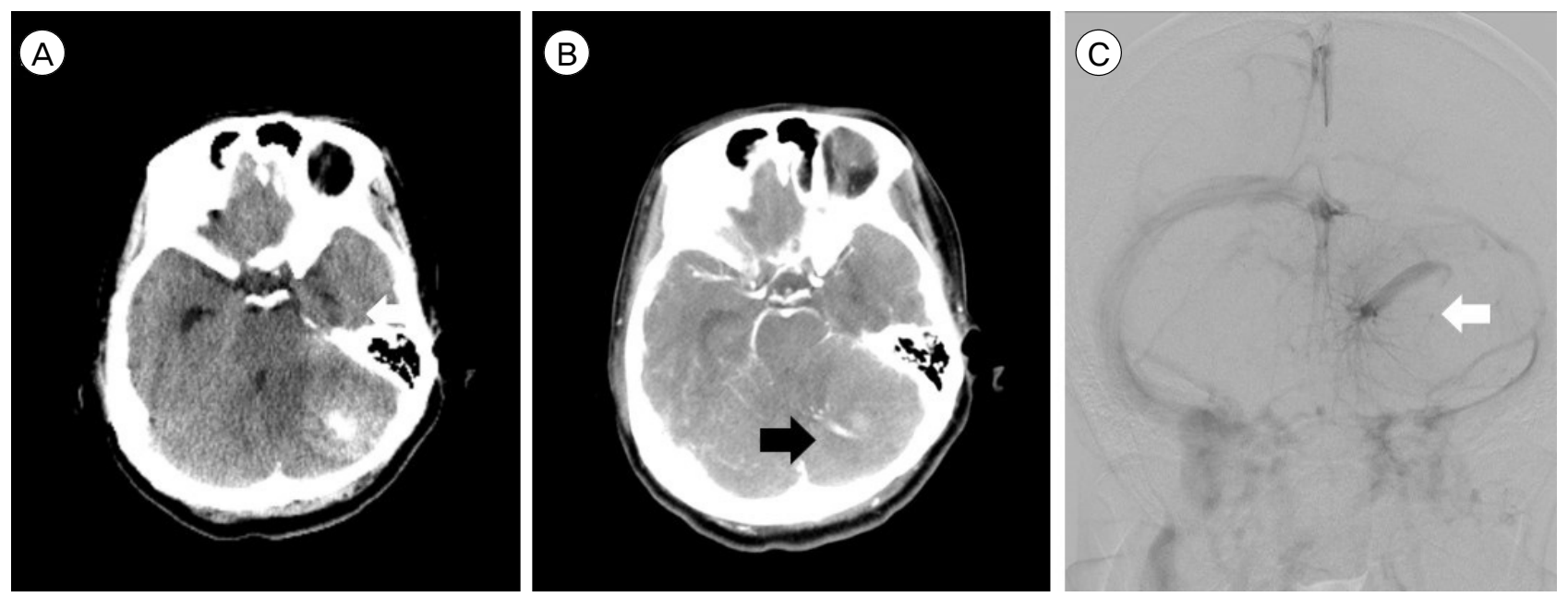

Fig. 2. A 46-year-old female with a developmental venous anomaly. (A) A NECT demonstrate ICH in the left cerebellum. (B) The CTA shows the 'spot sign (black arrow) within the hematoma. (C) An umbrella-shaped collection of dilated medullary veins, the so-called 'caput medusae' with a dilated transcortical vein (white arrow) is detected during the venous phase of the DSA.

\section{Case 3 .}

A 58-year-old man presented with IVH with the spot sign on CTA (Fig. 3). DSA showed a saccular pseudoaneurysm in the right posterior choroidal artery. It was successfully treated endovascularly.

\section{Case 4.}

A 15-year-old girl presented with ICH and IVH with the spot sign on CTA (Fig. 4). DSA showed an AVM with a round pseudoaneurysm in the left distal middle cerebral artery. The patient was treated surgically.

\section{DISCUSSION}

This is the first study to assess the correlation between the CTA spot sign and the existence of a possible vascular lesion using digital subtraction angiography. CTA is rapid, accessible, and widely available and can be used to predict prognosis and to decide upon a treatments on the basis of an initial emergency diagnosis. American Heart Association (AHA) guidelines suggest that CTA can be used to 

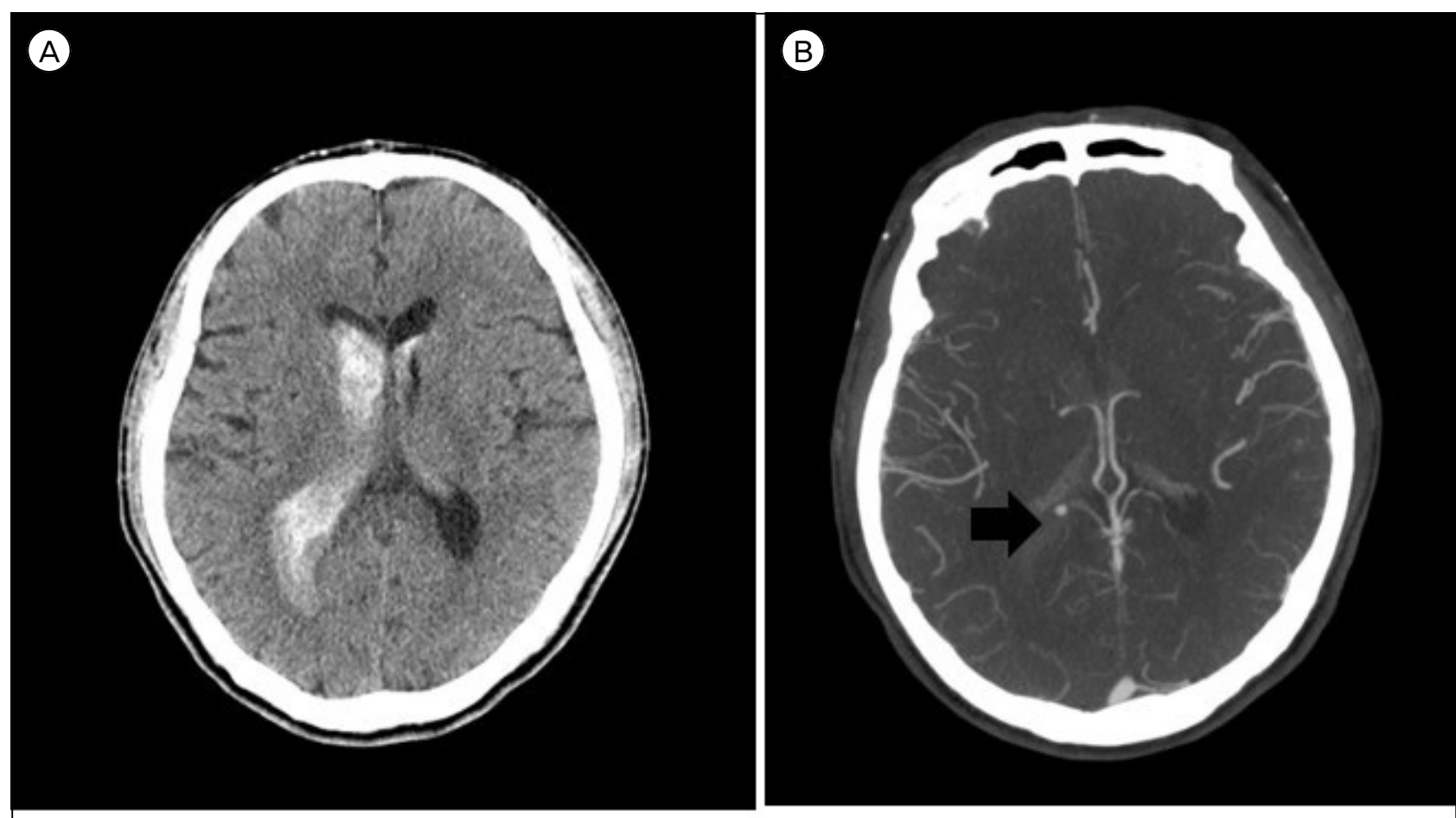

(C)

(D)

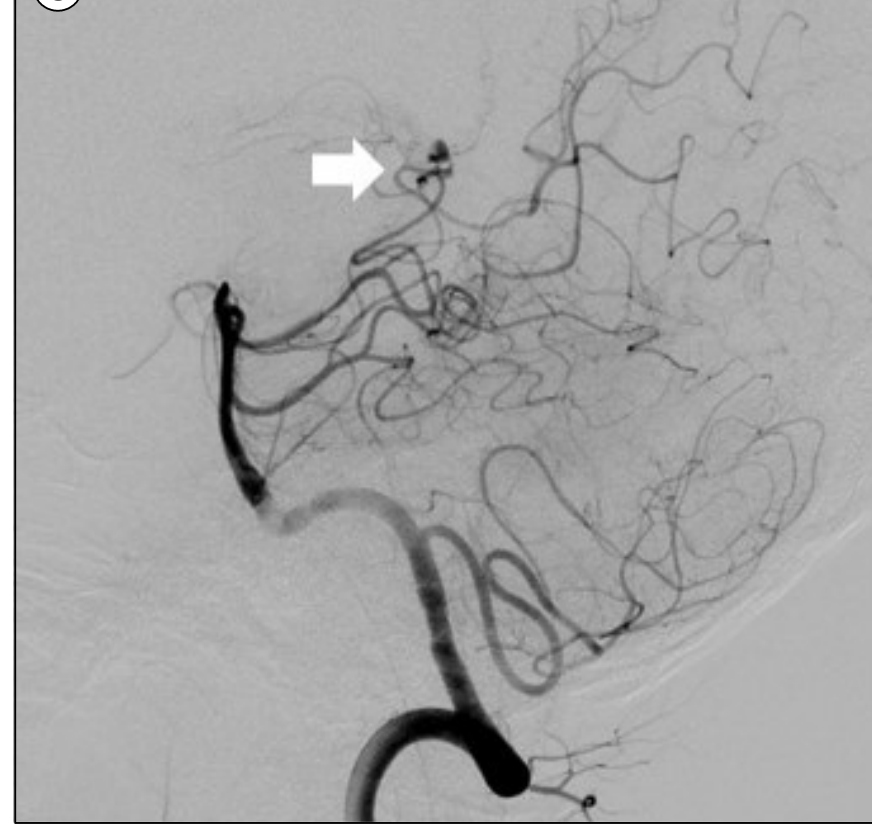

Fig. 3. A 58-year-old male with a pseudoaneurysm (A) NECT demonstrate pure IVH (B) CTA shows the spot sign (black arrow) in the right lateral ventricle. (C) A vertebral angiogram (lateral view) shows a pseudoaneurysm (white arrow) in the right posterior choroidal artery. (D) After embolization with glue, there is no more contrast filling in the pseudoaneurysm on DSA (White arrowhead).

help identify patients at risk and catheter angiography can be useful to search for underlying vascular structural lesions ${ }^{9}$. Hence, we focused on the in- formation obtained from the two diagnostic tools when patients who had spontaneous ICH with the spot sign were initially seen in the emergency room. 


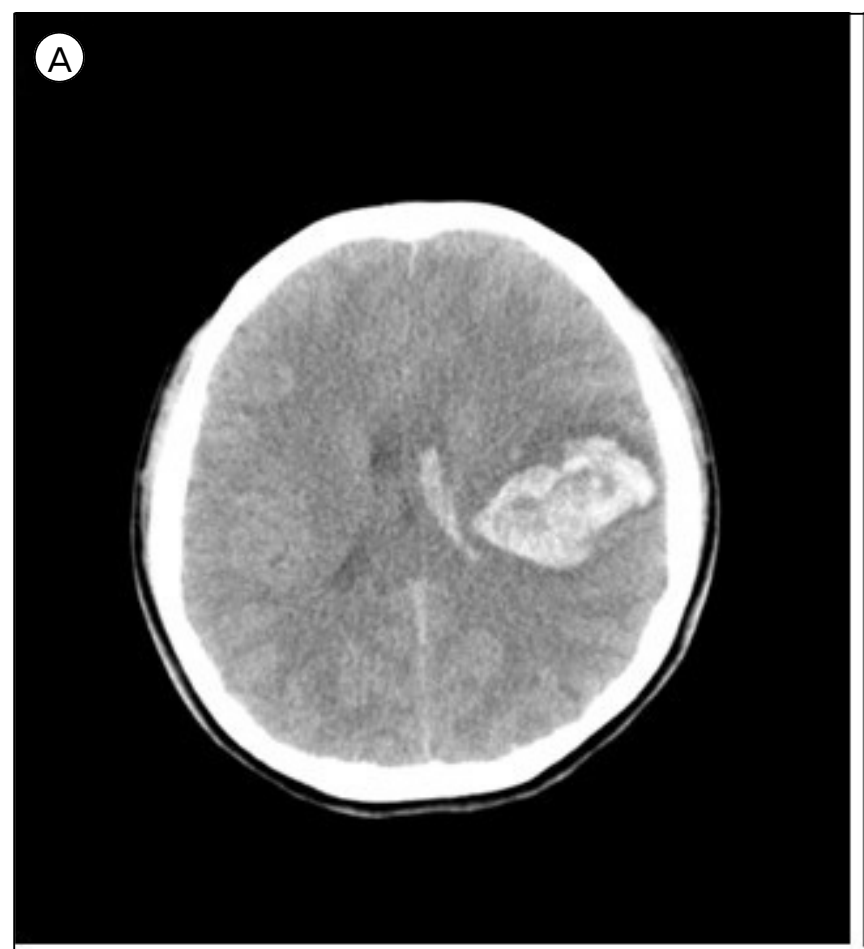

\section{B}

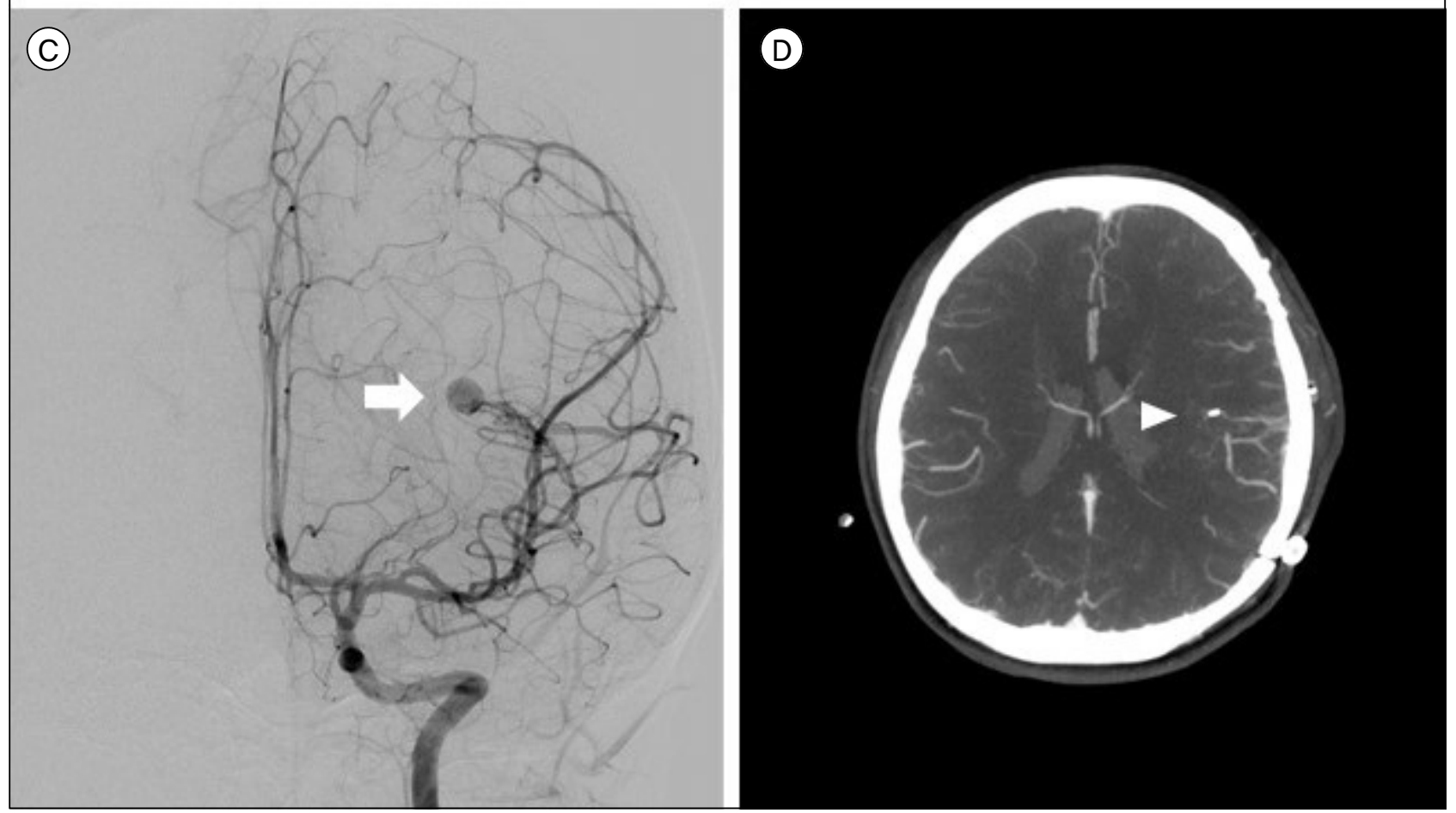

Fig. 4. A 15-year-old female with a pseudoaneurysm (A) NECT shows ICH in the right frontal lobe with IVH. (B) CTA shows the spot sign (black arrow) within the hematoma. (C) DSA (AP view) reveals an AVM with a pseudoaneurysm (white arrow). (D) After surgical treatment, there is no hematoma or pseudoaneurysm that showed contrast filling on the CTA MIP image (the white arrowhead is a post-operation hemo-clip).

Previous studies reported that the spot sign may have important implications for hematoma ex- pansion $^{335)}$ with sensitivity, specificity, positive, and negative predictive values of $91,89,77$ and $96 \%$, re- 
spectively ${ }^{18)}$. Chunyan Lei et al. reported that the presence of $\mathrm{IVH}$ is an independents predictors of mortality in $\mathrm{ICH}$ patients ${ }^{11)}$. In this study, DSA was performed to identify the cause of bleeding in the patients with the spot sign. Patients were divided into two groups according to the location of the spot sign and the results were compared clinically.

Steve Gazzole et al. assessed the prevalence of the CTA spot sign in cases of primary ICH and secondary ICH. They described mimics of the CTA spot sign and classified them as having vascular or nonvascular causes $^{7)}$. In their study, the causes of secondary $\mathrm{ICH}$ were defined as follows: AVM, dural AVF, tumor, aneurysm and Moyamoya disease. They reported 7 spot signs in 30 secondary $\mathrm{ICH}$ patients and three cases of tumoral hemorrhaging among those spot sign cases. However, in our study, tumor and aneurysm were excluded and we focused solely on the vascular lesions of the spot sign in the hemorrhages.

In our paper, as per the result of DSA in many cases $(17 / 26)$, there were no vascular lesions. Pseudoaneurysms and DVAs were detected by cerebral angiography in 7 cases and 2 cases, respectively. The current medical literature indicates an increased prevalence of incidental or asymptomatic DVAs with a low prevalence of $\mathrm{ICH}$ and a low morbidity and negligible mortality rate ( $\mathrm{ICH}$ prevalence, $0-3 \%$, morbidity, $0-10 \%)^{1214) 15)}$, but all DVAs in this study required surgical treatment. Presumably, predictive hematoma expansion and high mortality and morbidity are associated with ICH with the spot sign, separately accompanied by DVAs.

Various pathological or idiopathic states, including trauma, rupture of true aneurysms or AVMs, surgical and endovascular procedures, neoplasms, Marfan's syndrome, fibromuscular dysplasia, and vasculitis, which may lead to disruption of the arterial wall are possible causes of intracranial pseudoaneurysms ${ }^{1) 4}$. Pseudoaneurysms of the cerebral arteries are reported very rarely. Traumatic pseudoaneurysms are commonly located peripherally or near the base of the skull $^{19)}$. However, information on the locations of non-traumatic pseudoaneurysms and those due to other etiologies is not currently available. In our study, three of seven pseudoaneurysms (42.8\%) were located in the territory of the distal middle cerebral artery and two cases (28.5\%) were located in the posterior cerebral arteries. One pseudoaneurysm was located in the distal intracranial artery, and one was in the vertebral artery. (Table 1)

Lee A. Tan et al. reported that a ruptured lenticulostriate artery aneurysm, of which fewer than 50 cases have been reported in the literature ${ }^{8)}$, with the spot sign was clipped ${ }^{17)}$. Other authors published a case report on endovascular treatment of a pseudoaneurysm that formed due to rupture of an anterior communicating artery aneurysm ${ }^{10)}$. Because of their rarity, the natural history and optimal management of pseudoaneurysms are not well understood. Some papers have suggested that DSA is the gold standard for the diagnosis of cerebral pseudoaneurysms ${ }^{13)}$ and endovascular treatment represents a safe and durable procedure $^{2)}$; however, our results suggest that DSA is appropriate for verifying the pseudoaneurysm when CTA shows the spot sign in a ventricle.

We realize that the sample size in our study is too small to generalize the relationship between the spot sign and a pseudoaneurysm. This paper has a limitation in that patient' data were collected and analyzed retrospectively. Also, the definition of a pseudoaneurysm according to the shapes of angiogram is unclear, and we could not confirm the presence of a pseudoaneurysm pathologically because many cases underwent endovascular treatment. Another limitation of the study is loss to follow-up and comparison of results, complications, and prognosis among the different treatment groups.

\section{CONCLUSION}

It is known from previous studies that the spot sign and IVH are associated with hematoma expansion, 
and the correlation of pseudoaneurysms on DSA and the spot sign in the ventricle has been confirmed. When CTA shows the spot sign in a ventricle, it might be a clue that there is an existing underlying vascular lesion that requires endovascular treatment. In such cases, DSA can provide an accurate diagnosis leading to the proper course of treatment.

\section{REFERENCES}

1. Brzozowski K, Frankowska E, Piasecki $P$, Ziecina $P$, Zukowski P, Boguslawska-Walecka R. The use of routine imaging data in diagnosis of cerebral pseudoaneurysm prior to angiography. Eur J Radiol. 2011 Dec;80(3): e401-9.

2. Ciceri EF, Regna-Gladin C, Erbetta A, Chiapparini L, Nappini S, Savoiardo $M$, et al. Iatrogenic intracranial pseudoaneurysms: neuroradiological and therapeutical considerations, including endovascular options. Neurol Sci. 2006 Nov;27(5):317-22.

3. Davis SM, Broderick J, Hennerici M, Brun NC, Diringer $\mathrm{MN}$, Mayer SA, et al. Hematoma growth is a determinant of mortality and poor outcome after intracerebral hemorrhage. Neurology. 2006 Apr 25;66(8):1175-81.

4. de Andrade AF, Figueiredo EG, Caldas JG, Paiva WS, De Amorim RL, Puglia $P$, et al. Intracranial vascular lesions associated with small epidural hematomas. Neurosurgery. 2008 Feb;62(2):416-20; discussion 20-1.

5. Demchuk AM, Dowlatshahi D, Rodriguez-Luna D, Molina CA, Blas YS, Dzialowski I, et al. Prediction of haematoma growth and outcome in patients with intracerebral haemorrhage using the CT-angiography spot sign (PREDICT): a prospective observational study. The Lancet Neurology. 2012;11(4):307-14.

6. Dowlatshahi D, Wasserman JK, Momoli F, Petrcich W, Stotts G, Hogan M, et al. Evolution of computed tomography angiography spot sign is consistent with a site of active hemorrhage in acute intracerebral hemorrhage. Stroke. 2014 Jan;45(1):277-80.

7. Gazzola S, Aviv RI, Gladstone DJ, Mallia G, Li V, Fox $\mathrm{AJ}$, et al. Vascular and nonvascular mimics of the CT angiography "spot sign" in patients with secondary intracerebral hemorrhage. Stroke. 2008 Apr;39(4):1177-83.

8. Heck O, Anxionnat R, Lacour JC, Derelle AL, Ducrocq X, Richard S, et al. Rupture of lenticulostriate artery aneurysms. J Neurosurg. 2014 Feb;120(2):426-33.
9. Hemphill JC, 3rd, Greenberg SM, Anderson CS, Becker $\mathrm{K}$, Bendok BR, Cushman M, et al. Guidelines for the Management of Spontaneous Intracerebral Hemorrhage: A Guideline for Healthcare Professionals From the American Heart Association/American Stroke Association. Stroke. 2015 Jul;46(7):2032-60.

10. Ito $\mathrm{H}$, Morishima $\mathrm{H}$, Onodera $\mathrm{H}$, Wakui $\mathrm{D}$, Uchida $\mathrm{M}$ Sase $\mathrm{T}$, et al. Acute phase endovascular intervention on a pseudoaneurysm formed due to rupture of an anterior communicating artery aneurysm. J Neurointerv Surg. 2015 Mar;7(3):e9.

11. Lei C, Wu B, Liu M, Cao T, Wang Q, Dong W. Differences Between Vascular Structural Abnormality and Hypertensive Intracerebral Hemorrhage. J Stroke Cerebrovasc Dis. 2015 8//;24(8):1811-6.

12. McLaughlin MR, Kondziolka D, Flickinger JC, Lunsford $\mathrm{S}$, Lunsford LD. The prospective natural history of cerebral venous malformations. Neurosurgery. 1998 Aug;43(2):195-200; discussion -1.

13. Murias Quintana E, Gil Garcia A, Vega Valdes $P$, Meilan Martinez A, Botana Fernandez M, Gutierrez Morales JC, et al. [Our experience in the diagnosis and treatment of cerebral pseudoaneurysms]. Radiologia (Roma). 2012 Jan-Feb;54(1):65-72.

14. Naff NJ, Wemmer J, Hoenig-Rigamonti K, Rigamonti DR. A longitudinal study of patients with venous malformations: documentation of a negligible hemorrhage risk and benign natural history. Neurology. 1998 Jun;50(6): 1709-14.

15. Rammos SK, Maina R, Lanzino G. Developmental venous anomalies: current concepts and implications for management. Neurosurgery. 2009 Jul;65(1):20-9; discussion 9-30.

16. Romero JM, Kelly HR, Delgado Almandoz JE, Hernandez-Siman J, Passanese JC, Lev MH, et al. Contrast extravasation on CT angiography predicts hematoma expansion and mortality in acute traumatic subdural hemorrhage. AJNR Am J Neuroradiol. 2013 Aug;34(8): 1528-34.

17. Tan LA, Kasliwal MK, Johnson AK, Lopes DK. The "Spot Sign" secondary to a ruptured lenticulostriate artery aneurysm. Clin Imaging. 2014 Jul-Aug;38(4):508-9.

18. Wada R, Aviv RI, Fox AJ, Sahlas DJ, Gladstone DJ, Tomlinson G, et al. CT angiography "spot sign" predicts hematoma expansion in acute intracerebral hemorrhage. Stroke. 2007 Apr;38(4):1257-62.

19. Wang X, Chen JX, You C, He M. Surgical management of traumatic intracranial pseudoaneurysms: a report of 12 cases. Neurol India. 2008 Jan-Mar;56(1):47-51. 